\title{
Brain stimulation used as biofeedback training for recovery of motor functions deteriorated by stroke
}

\author{
A estimulação cerebral em pacientes com acidente vascular cerebral está associada a \\ melhoria no desempenho motor e a incremento de eficácia na função neuronal \\ Mauricio Rocha Calomeni ${ }^{6}$, José Antonio Martins da Silva Rocha², Alair Pedro Ribeiro da Silva ${ }^{3}$, \\ Luiz Henrique Brandão Ribeiro4, Luciene Marques ${ }^{4}$, Maria Auxiliadora Freire Siza ${ }^{5}$, Vernon Furtado da Silva ${ }^{1}$
}

\begin{abstract}
According to World Health Organization, approximately 15 million people are affected by cerebrovascular accident in the world. We study the effect of brain stimulation plus an imaging procedure used as biofeedback training for recovery of motor functions impaired by CVA. Four individuals aged between 33 and 72 years were included in the study, of both genders, with hemiparesis on the left arm due to the CVA. They had their brain activity monitored by EEG. Functional tasks were evaluated according to an observational model proposed by the international classification of functioning and by runtime. The training was composed of 12 sessions of 30 minutes of stimulation by light and sound, as well as imaging procedures. Results revealed that improvements in the performance of the task, with regard to both the runtime and the functional quality of movements, are more related to the increase of effectiveness of neuronal function.
\end{abstract}

Key words: stroke, motor neurons, deep brain stimulation.

\section{RESUMO}

Segundo a Organização Mundial da Saúde, aproximadamente 15 milhões de pessoas no mundo sofrem acidente vascular cerebral (AVC). Estudaram-se os efeitos da estimulação cerebral associada à imagética, como treinamento de biofeedback, para a recuperação das funções motoras deterioradas pelo AVC. Foram incluidos 4 indivíduos com idade entre 33 e 72 anos, de ambos os gêneros, e com hemiparesia no braço esquerdo devido ao AVC. Esses pacientes tiveram a atividade cerebral monitorada por EEG. A tarefa funcional foi avaliada de acordo com o modelo de observação proposto pela Classificação Internacional de Funcionalidade e pelo tempo de execução. 0 treinamento consistiu de 12 sessões de 30 minutos de estimulação por luz e som associado à imagética. Os resultados revelaram melhoria no desempenho da tarefa, tanto em relação ao tempo de execução quanto à qualidade funcional do movimento, e que está mais relacionada com o incremento de eficácia da função neuronal.

Palavras-Chave: acidente vascular cerebral, neurônios motores, estimulação encefálica profunda.

As evidence by the World Health Organization ${ }^{1}$, annually, about 15 million people are affected by cerebrovascular accidents (CVA), also known as stroke, with almost one-third of them suffering from some sort of disability. Consequences of CVA can be observed from a deep neural examination and may be presumed as the effect of the destruction of previously existing communications among a myriad of neurons responsible for the vandalized functions.

The possible restoration could be presumed as being at the order of some sophisticated organic process normally under the conception of human brain neural plasticity ${ }^{2-4}$. In addition, in a theoretical point of view, one may expect that

${ }^{1}$ PhD, Head of Laboratório de Aprendizagem Neural e Performance Motora (LANPEM/CNPq), Universidade do Estado do Rio de Janeiro (UERJ); Coordinator of a research group on Neural processes and mechanisms (CNPq), Rio de Janeiro RJ, Brazil;

${ }^{2}$ PhD, Post-graduation Professor at Universidade de Trás Montes e Alto Douro, Portugal;

${ }^{3} \mathrm{PhD}$, Coordinator at Laboratório de Mapeamento Cerebral e Integração Sensório Motora do Instituto de Neuropsiquiatria, Universidade Federal do Rio de Janeiro (IPUB/UFRJ), Rio de Janeiro RJ, Brazil;

${ }^{4} \mathrm{PhD}$ student at Universidade de Trás dos Montes e Alto Douro, Portugal;

${ }^{5}$ Professor at Centro Universitário de João Pessoa (UNIPÊ); PhD student at Universidade de La República(UdelaR);

${ }^{6}$ Researcher at LANPEM/CNPq; Full member of CENSA (ISE-CENSA);

Correspondence: Mauricio Rocha Calomeni; Rua Frei Vitório 186; 28400-000 São Fidélis RJ - Brasil; E-mail: mauriciocalomeni@gmail.com

Conflict of interest: There is no conflict of interest to declare.

Received 10 June 2012; Received in final form 13 September 2012; Accepted 20 September 2012. 
when improving stimulation for synaptic activity the gain in synaptic consolidation is a normal and expected result ${ }^{5,6}$.

From the basic neural literature, it is known that the more we think the higher will be the activation of the neurons operating our related thought. In most of the cases, neurons insistently proceeding in a decoding manner can promote more elaborated results in synaptic proliferation than can those operating in a superficial way ${ }^{7}$. In this regard, Lameira, Gawryszewski and Pereira Júnior ${ }^{8}$ stated that the circuits of neurons that are active in a motor task performed by someone would be the same ones used by the individual when watching another person doing the same thing. That is, the task performance by oneself as well as the observation of its execution by another individual are related to the activation of the same group of neurons in the brain of the performer/ observer $^{4,9}$.

In many situations, it may not be simple for individual that go through a CVA to produce significant neural impulses load, considering that a CVA almost always produces synaptic deterioration in the respective brain area affected ${ }^{10}$.

Brain stimulation procedure using photic and auditory synthesizers is a type of deep brain stimulation by noninvasive and easy-to-apply technique. Researchers in this line of investigation have proved the benefits of this simple procedure applied to a series of treatment for neuromotor disorders, such as Parkinson's disease ${ }^{11-13}$, as well as other behavioral treatments ${ }^{14,15}$.

The study's rationale was that if stimulation could, in fact, improve neural activity in the neurons associated with the functional task training, then its imagery would be more accurate, and consequently the performance of the task would improve. We also rationalized that comparison of the subjects' electroencephalographic (EEG) recordings when doing and watching the experimental functional task performance would give us a basis for the identification of neural sites where the predicative changes could occur.

\section{METHODS}

The study took into account the present natural characteristics of the participants, and due to the small number of participants and the absence of a control group, it can be considered a case pretrial study. As such, the study was evaluated and approved by the ethics committee of The CENSA Institute for High Learning., under the protocol number 0037.0.413.000-10.

The sample included 4 individuals aged between 33 and 72 years, comprising both the genders and featuring hemiparesis in left arm due to CVA, with time of injury between 8 and 60 months. All individuals agreed to participate in the study and signed an informed consent form. The exclusion criteria for this study were adopted taking into account the subjects' possible cognitive and motor impairments, including processes of dementia, uncontrolled depression, hypertension, musculoskeletal disorders in the left arm, and visual and/or auditory disorders. The first dependent variable measured was the level of neurons activity as related to the area where the electrodes were positioned on the head of the patient. The recordings for comparisons were those obtained when a tested subject performed the experimental functional task as well as the same task performed by another person (mirror neurons common protocol) was observed. The other two dependent variables were the level of functionality of subject's upper limbs and the time of experimental task execution. The recording of neuron activation was made using a biofeedback system associated with a neurocomp instrument. Two specific channels were used for recording EEG data. As recommended by the instrumental methodology, ideal conditions and safe grounding were provided to avoid energy dispersion, interference, and/or any type of noise in the recording data.

The experimental functional task was measured according to an observational model proposed by the international classification of functioning (ICF), in which performance can be observed at five interrelated levels. The most valuable pattern was related to an execution completed without any problems $(0-4 \%)$ and the less valuable pattern was the one when severe problem was observed in the performer's actions (96-100\%). Intermediate levels were mild problems (5-24\%), moderate problems (25-49\%), and severe problems (50-95\%). This specific evaluation was done by inviting 10 people unrelated to the study for training the experimental functional task. Then the subjects were observed while doing the task before and after the intervention process, and the two performances were compared with a video of the researcher carrying out the same task without difficulty. Subsequently, the subject's performances were graded in the two instances of the experimental task. To facilitate judgment, evaluators received instructions to rate the performance as very bad, bad, regular, good, and very good, with each rate respectively related to the ICF rating format.

Each video was classified by 10 specialists, and the mostly attributed level was considered as the functional state of the subjects. The task execution time was taken from the moment the subjects, at the researcher's command, moved the left upper limb from a start position, picked up, and took a cup to the mouth, returned the cup to a marked position, and brought back the hand to the start position. The score adopted for this research step was the mean of six attempts made. Finally, the cerebral stimulation was applied by means of two procedures occurring simultaneously: photic and audio conjugated synthesized wave frequencies whose protocol emphasized the activation of a specific brain area to be measured by the EEG procedure. Details of the instrumentation and protocol used can be found elsewhere ${ }^{16}$. This procedure 
was conjugated with a brain motor imaging protocol whose rationality for mental imaging has been cited by Hanakawa et $\mathrm{al}^{17}$ as an active process in which actions mentally produced may result in a similar activation produced in the area where an identical activation is noted in motor execution.

All the study phases were carried out in a room carefully prepared, at a temperature maintained at about $21^{\circ} \mathrm{C}$. All possible noise was carefully controlled (avoided). The training period comprised 12 sessions of 30 minutes of stimulation by light and sound, as well as imaging procedure. The intervention phase was applied three times a week in alternate days.

At the beginning of the evaluation, the subject was invited to sit comfortably on a chair with a rectangular table in front of him/her. After prior aseptic procedure, the researcher positioned the electrodes in the subject's scalp. This positioning was performed according to the International system 10-20, in accordance with the Brazilian Society for Clinical Neurophysiology. The points chosen were C4 (right parietal cortex), and the reference points A1 (auricle left) and A2 (auricle right). The equipment monitored the pattern of brain activity during two specific moments of the task.

The task chosen required the subject to take an empty plastic cup toward his/her mouth (as drinking), and in the second moment, he/she had to observe the researcher doing the same task. In both the cases, the total time for task accomplishment was 2 minutes. During the task observation phase, the subject had to stay immobile, observing the researcher and imagining himself/herself doing the task (motor imaging). Thus, during this phase, the EEG recordings were obtained from the subject's prefrontal cortex as he/she observed and imagined herself/himself doing the drinking task. For research purposes, this was the moment in which the assumptions for mirrors neuron reciprocal cerebral activation could be tested.

For the second part of the study, i.e., for testing the possibility of the cerebral stimulation effectiveness, the subject, during test/training, had to sit on a chair with each hand resting on the respective side leg. On a table in front of the subject, an empty plastic cup was placed. The subject had to raise the upper left hand above the table, grab the cup, lead it to the mouth, return the cup to the support table, and move back the left hand to its original resting position. This procedure was executed on a six testing trial basis, with a 30 -second interval between the six trials, which were filmed for further qualitative analysis. The functional level of the upper left hand action was classified according to the ICF, and the score ranged from very bad, bad, regular, and good.

The moment of intervention occurred through the photic and hearing stimulation in bands of frequencies of 8,9 , and $11 \mathrm{~Hz}$, all in alpha frequency, with the objective of equalization of the brain activity in a state favorable for learning and concentration. The distribution of stimulation obeyed the order of 5 minutes in $8 \mathrm{~Hz}, 5$ minutes in $9 \mathrm{~Hz}$, and more than 10 minutes in $11 \mathrm{~Hz}$, which is the moment when the motor imagery protocol was initiated. After 20 minutes of stimulation, the equipment was turned off. At this specific moment, the subject was blindfolded and the motor imagery protocol was continued for 10 more minutes. During the motor imagery, the subject was motivated to remember the sequence of movements held in the task.

The last moment corresponded to the final evaluation, a period during which all of the procedures used in the initial assessment were repeated. All the data obtained in the initial assessment were individually compared with the final results of the subjects. The records of the neuronal activity during motor imagery (mirror neurons) and real task execution (neurons responsible for the task) collected through the EEG were converted to quantitative data whose values were expressed in millivolts $(\mathrm{mV})$. As the current research was a case study, we did not use inferential statistics for the treatment of the EEG data, because the objective was to observe the possible changes in the neuronal activity of the subjects, revealing the functional gains produced during the proposed intervention. On the other hand, this type of statistic instrument was used to determine statistically significant differences in the pre and post-intervention gains. In order to do that, the Shapiro-Wilk test was used to analyze the scores' normality, as well as the Wilcoxon nonparametric test. The statistical tests were carried out by setting an alpha value of 0.05 .

\section{RESULTS}

The results presented in Figure are the task execution times. The plotted values in the figure refer to the time, in seconds, spent during task execution.

In all subjects, the applied intervention resulted in a significant reduction in the time required for task execution. This particular result could be interpreted as associated with some type of plastic reorganization in the motor cortex responsible for task organization and execution. The subjects' scores in the ICF assessment are shown in Table 1.

Comparing the results presented in the Figure and those presented in Table 1, one may observe that only Subject 3 did not obtain significant improvement in ICF.

Table 2 shows the descriptive analysis of the activation of subjects' right cortex of the mirror neurons site through the observation and simultaneous imagery of the task in both the moments of pre and post-test execution.

From the table, it can be noted that in relation to mirror neurons that occurred on an average, a reduction in the activation between the pre and post-intervention is associated with a small increase in the standard deviation. Moreover, it can also be observed that Subject 3 exhibited less influence regarding the mirror neurons activation. 

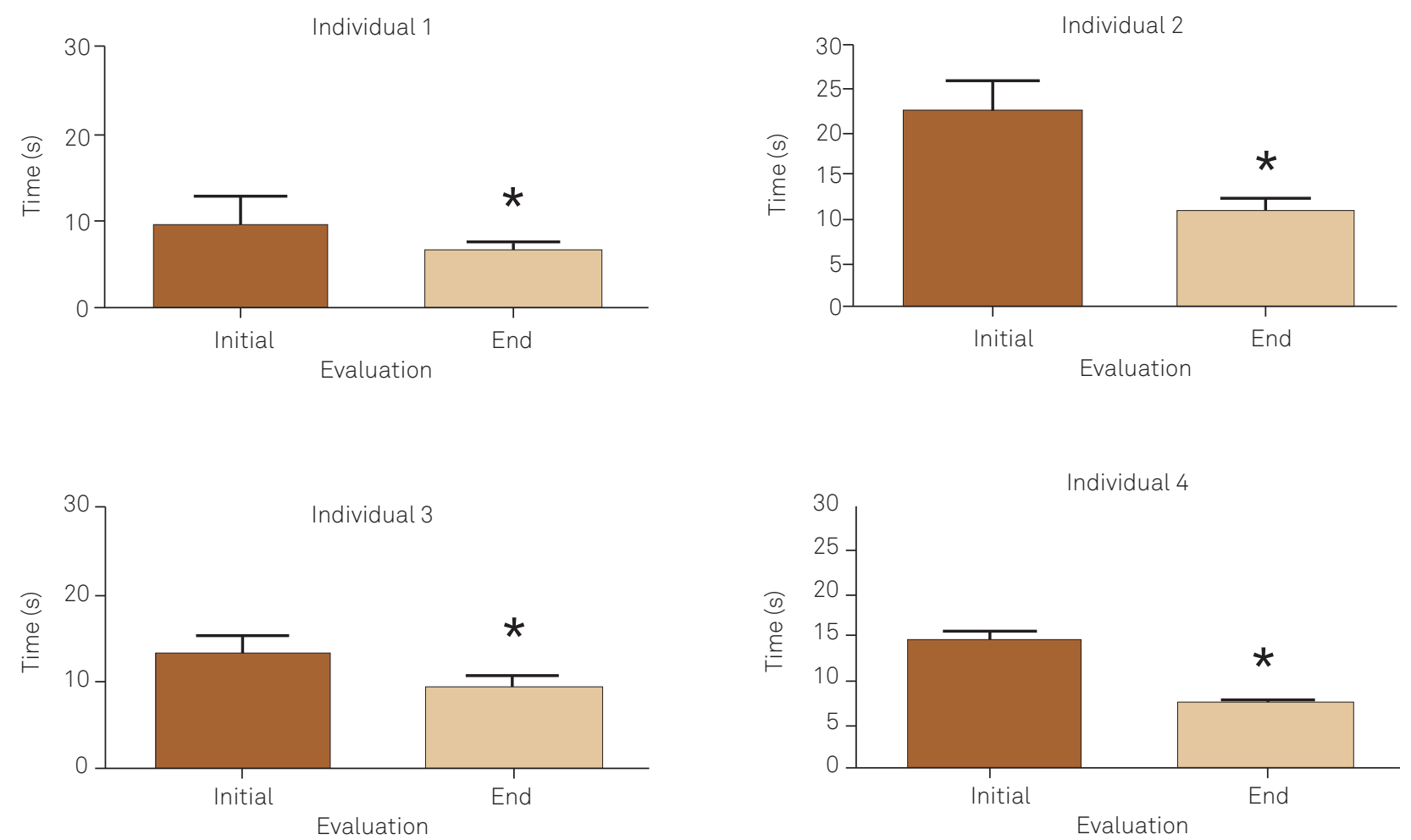

*Indicates significant decrease $(p<0.05)$.

Figure. Plotted of the times of task execution obtained in initial and end assessment. The data presented express a mean of the scores obtained in attempts recorded.

Table 1. Level of difficultyinthetaskaccordingwith ICFindicating the quality of the movement executed in the proposed task.

\begin{tabular}{ccc} 
& Pretest assessment & Post-test assessment \\
\hline Subject 1 & Severe problem & Mild problem \\
& d560.3 & d560.1 \\
Subject 2 & Severe problem & Moderate problem \\
& d560.3 & d560.2 \\
Subject 3 & Moderate problem & Moderate problem \\
& d560.2 & d560.2 \\
Subject 4 & Moderate problem & Mild problem \\
& d560.2 & d560.1 \\
\hline
\end{tabular}

ICF: International Classification of Functioning, Disability and Health, d.560 $(1,2,3)$ level of difficulty.

From Table 3, by comparing the subjects' task execution before and after intervention, there is a small increase in the neuronal activation average and a significant reduction in the related standard deviation. Thus, we can conclude that during the real task execution, neuronal activation of the observed area was more efficient when considering the significant homogeneity, as expressed by the concomitant reduction in standard deviation.

\section{DISCUSSION}

Cattaneo and Rizzolatti ${ }^{18}$ showed that mirror neurons also participate in motor learning. Other researchers have shown that while observing various actions, an increase in the motor-evoked potential occurs ${ }^{19-21}$. These findings support the data presented in Table 2, which refer to the supposed activation of mirror neurons of the right hemisphere (RH) during the observation task. As observed in the post-intervention phase, there was an averaged increase in the activation of neurons of Subjects 1 and 2, demonstrating a greater number of mirror neurons being activated. Furthermore, the records show decreased activation in Subjects 3 and 4, which could be owing to a possible dispersion of the subject's focus when observing the task being performed by the other person who participated as model. It has been shown that to activate a person's mirror neurons, the observer must be in focus with the action being observed. On the other hand, it seems that the constant reduction in standard deviation, observed in the other subjects' scores (not observed in only Subject 2) can be attributed to a possible functional improvement in those subjects' mirror neurons as a result of their $\mathrm{RH}$ intervenient stimulation.

More conclusive observations can be made by examining the data of $\mathrm{RH}$ motor neurons activation during task execution in pre and post-intervention. Subjects 1 and 4 showed reduction in neurons activation during the task, which may indicate maximum efficiency in the selection of neurons for the same task, signifying motor learning. However, in Subjects 2 
Table 2. Descriptive data of extremes, average, and standard deviation during the activation of mirror neurons in pre- and posttest. Data expressed as millivolts ( $\mathrm{mV})$.

\begin{tabular}{|c|c|c|c|c|}
\hline Pretest assessment & Minimum & Peak & Average & Standard deviation \\
\hline Subject 1 & 11.59 & 226.30 & 24.45 & 23.52 \\
\hline Subject 2 & 15.20 & 87.58 & 48.27 & 15.82 \\
\hline Subject 3 & 2.83 & 113.98 & 5.80 & 5.67 \\
\hline Subject 4 & 9.16 & 332.58 & 57.63 & 25.05 \\
\hline \multicolumn{5}{|l|}{ Post-test assessment } \\
\hline Subject 1 & 9.55 & 85.14 & 28.37 & 12.17 \\
\hline Subject 2 & 38.67 & 611.09 & 61.49 & 52.79 \\
\hline Subject 3 & 1.95 & 67.41 & 5.02 & 3.81 \\
\hline Subject 4 & 4.19 & 88.26 & 13.35 & 7.66 \\
\hline
\end{tabular}

Table 3. Data of extremes, average and standard deviation of the activation of neurons during real execution of task in pre- and post-test. Data expressed as millivolts (mV).

\begin{tabular}{lcccc} 
Pretest assessment & Minimum & Peak & Average & Standard deviation \\
\hline Subject 1 & 11.59 & 226.30 & 24.45 & 23.52 \\
Subject 2 & 15.20 & 87.58 & 48.27 & 15.82 \\
Subject 3 & 2.83 & 113.98 & 5.80 & 5.67 \\
Subject 4 & 9.16 & 332.58 & 57.63 & 25.05 \\
\hline Post-test assessment & & & & 28.37 \\
\hline Subject 1 & 9.55 & 85.14 & 61.49 & 12.17 \\
Subject 2 & 38.67 & 611.09 & 5.02 & 52.79 \\
Subject 3 & 1.95 & 67.41 & 13.35 & 3.81 \\
Subject 4 & 4.19 & 88.26 & 7.66 \\
\hline
\end{tabular}

and 3, there was an increase in the activation of motor neurons, which may be owing to an increase in the recruitment of neurons for the task, with a purpose to complete the task more efficiently. This apparent divergence in the analysis can be considered as a neuroplastic process, and this process has several characteristic stages of change. In agreement with this, Barato $^{4}$ stated that the brain has different routes for reorganization, depending on the damaged area. As observed in the analysis of mirror neurons, in the neurons activated during the task, it is possible detect an interesting trend with respect to standard deviation. All subjects showed a significant reduction in the variation of data, except Subject 3. This may indicate a more balanced, more efficient standard of activation. The lower rate of improvement in the ICF observed in Subject 3 was due to the fact that besides being under the lowest duration of treatment for injury, the subject was also the oldest among the others included in the study. It is known that the elderly have reduced processing resources, which leads to a decline in the performance on tests of memory, learning, and motor performance. In addition, the elderly have difficulty in inhibiting or blocking the entry of irrelevant information during processing, a condition which may result in loss of concentration and focus during task performance ${ }^{22}$. In addition, the aging process causes cortical atrophy, a neuronal death caused by physiological constraints, which is aggravated when associated with lesions in the central nervous system.

In conclusion, the study showed that improvement in task performance, with regard to both the time of execution of the task itself, as well as the functional quality of movement, is more related to the effective operation of neurons. This effective operation was represented by a reduction in the standard deviation, and the activation of a greater number of neurons during the task was represented by an increase in the electrical activity in the evaluated points.

\section{References}

1. WHO - World Health Organization. The atlas of heart disease and stroke. Reino Unido, 2004.

2. Oliveira CEN, Salina ME, Annunciato NF. Fatores ambientais que influenciam a plasticidade do SNC. Rev Acta Fisiátr 2001;8:6-13.

3. Oda JY, Sant'ana DMG, Carvalho J. Plasticidade e regeneração funcional do sistema nervoso: contribuição ao estudo de revisão. Arq Ciênc Saúde Unipar 2002;6:171-176.

4. Barato G, Fernandes T, Pacheco M, et al. Plasticidade cortical e técnicas de fisioterapia neurológica na ótica da neuroimagem. Rev Neurocienc 2009;17:342-348.
5. Matsuzaki M, Honkura N, Ellis-Davies GCR, Kasai H. Structural basis of long-term potentiation in single dendritic spines. Nature 2004;429:761-766.

6. Boric K, Muñoz P, Gallagher M, Kirkwood A. Potential adaptive function for altered long-term potentiation mechanisms in aging hippocampus. J Neurosc 2008;28:8034-8039.

7. Zanon RG, Emirandetti A, Simões GF, et al. Expressão do complexo de histocompatilidade principal de classe I (MHC I) no sistema nervoso central: plasticidade sináptica e regeneração. Coluna/Columna 2010;9:193-198. 
8. Lameira AP, Gawryszewski LG, Pereira Júnior A. Neurônios espelhos. Rev Psicol USP 2006;17:123-133.

9. Fabbri M, Rizzolatti G. Mirror neurons and mirror systems in monkeys and humans. Am Physiol Soc 2009;23:171-179.

10. Liu J, Xu D, Ren Y, Zhang LQ. Evaluations of neuromuscular dynamics of hyperactive reflexes poststroke. J Rehabil Res Dev 2011:48:577-586.

11. Del Olmo F, Arias MP, Mazaira JC. Facilitación de la actividade motora por estímulos sensoriales em la enfermedad de Parkinson. Rev Neurologior 2004;39:841-847.

12. Jakubovic BKM, Carraro ERRO, Vieira G, et al. Efeitos de sintetizadores de ondas cerebrais na doença de Parkinson. Efdeportes Rev Digital Buenos Aires - Año 14 - No 139 - Deciembre de 2009.

13. Carraro ERO, Frazão ACDD, Soares KVBC, Silva Vernon F. Estimulação cerebral por sintetização fótica e auditiva associada à imagética e massoterapia: minimização de dor em mulheres portadoras de fibromialgia. Motriz (Rio Claro) 2010;16:359-369.

14. Joyce M, Siever D, Twittey M. Audiovisual entrainment program as a treatment for behavior disorders in a school setting. J Neurother 2000;4:9-25.
15. Marques LJ, Silva Veron F, Silva APRS, Albergaria MB. Padrão de atividade cortical ótima para aprendizagem hábil-motriz e cognitiva. Fitness Performance J 2006;3:177-186.

16. Silva Vernon F, Calomeni MR, Rocha JAMS, et al. Pruebas neuropsicológicas: precisión de diagnóstico de la enfermedad de alzheimer en comparación con el examen de diagnóstico por eeg cuantitativo (EEGc). Rev Motr Hum 2010;11:59-66.

17. Hanakawa T, Immisch I, Toma K, Dimyan MA, Gelderen PV, Hallett M. Functional properties of brain areas associated with motor execution and imagery. J Neurophysiol 2003;89:989-1002.

18. Cattaneo L, Rizzolatti G. The mirror neuron system. Arch Neurol 2009;66:557-560.

19. Rizzolatti G, Arbib MA. Language within our grasp. Trends Neurosc 1998;21:188-194.

20. Rizzolatti G, Craighero L. The mirror neuron system. Ann Rev Neurosc 2004;27:169-192.

21. Chong TTJ, Cunnington R, Williams MA, Kanwisher N, Mattingley JB. fMRI adaptation reveals mirror neurons in human inferior parietal cortex. Current Biol 2008;18:1576-1580.

22. Freitas EV, Py L, Cançado FAX, Doll J, Gorzoni ML. Tratado de geriatria e gerontologia. 2. ed., Rio de Janeiro: Guanabara-Koogan, 2006. 